\title{
COMPOSITION OF TWO SEAWEED-OLIGOSACCHARIDE-LYSATES DERIVED FROM AGARASE AS-II AND THEIR FERROUS-CHELATING ANTIOXIDANT POWER
}

Fu-Jin Wang

Department of Tourism, Aletheia University, Taipei, Taiwan, R.O.C.

Sheen-Kye Kang

Department of Food Science, National Taiwan Ocean University, Keelung, Taiwan, R.O.C.

Chorng-Liang Pan

Department of Food Science, National Taiwan Ocean University, Keelung, Taiwan, R.O.C.

Shao-Chi Wu

Department of Food Science and Technology, Tung-Fang Design University, Kaohsiung, Taiwan, R.O.C., agarase@msn.com

Follow this and additional works at: https://jmstt.ntou.edu.tw/journal

Part of the Life Sciences Commons

\section{Recommended Citation}

Wang, Fu-Jin; Kang, Sheen-Kye; Pan, Chorng-Liang; and Wu, Shao-Chi (2011) "COMPOSITION OF TWO SEAWEEDOLIGOSACCHARIDE-LYSATES DERIVED FROM AGARASE AS-II AND THEIR FERROUS-CHELATING ANTIOXIDANT POWER," Journal of Marine Science and Technology. Vol. 19: Iss. 5, Article 12.

DOI: $10.51400 / 2709-6998.2170$

Available at: https://jmstt.ntou.edu.tw/journal/vol19/iss5/12

This Research Article is brought to you for free and open access by Journal of Marine Science and Technology. It has been accepted for inclusion in Journal of Marine Science and Technology by an authorized editor of Journal of Marine Science and Technology. 


\title{
COMPOSITION OF TWO SEAWEED-OLIGOSACCHARIDE-LYSATES DERIVED FROM AGARASE AS-II AND THEIR FERROUS-CHELATING ANTIOXIDANT POWER
}

\author{
Fu-Jin Wang*, Sheen-Kye Kang**, Chorng-Liang Pan**, and Shao-Chi Wu***
}

Key words: $\beta$-agarase, antioxidative activity, neoagarohexaose, neoagarotetraose.

\begin{abstract}
Seaweed-oligosaccharide-lysates (SwOSLys) Gra-C108, Mon-C108, Gra-AS-II, or Mon-AS-II are seaweed polysaccharide extracts (SwPSExts) Gra or Mon, which are digested by either Aeromonas (A.) salmonicida MAEF108 crude agarases or Agarase AS-II that was produced from marine bacteria A. salmonicida MAEF108. High-performance liquid chromatography revealed that there were neoagarohexaose and neoagarotetraose in both Gra-C108 and Gra-AS-II and that neoagarooligosaccharide was absent in both Mon-C108 and Mon-AS-II. The polyphenol content of SwOSLys was higher than that of SwPSExts, though without significant difference $(p<0.05)$ on lysates, as digested by crude MAEF108-agarases or Agarase AS-II. Comparison of the chelating effects of GraC108 and Gra-AS-II on $\mathrm{Fe}^{2+}$ shows that not only do the polyphenolic compound but also the neoagarooligosaccharide show antioxidative properties.
\end{abstract}

\section{INTRODUCTION}

Oxidative stress has been reported to be a result of an imbalance that occurs when a survival mechanism is unable to adequately deal with a reactive oxygen species (ROS) present in the cells [2]. The interest in ROS in biology and medicine stems from their strong relationship with phenomena, such as Alzheimer's disease, arthritis, cancer, cardiovascular diseases, diabetes, tissue damage caused by ischemia-reperfusion, and Parkinson's disease [12].

Paper submitted 02/24/10; revised 09/10/10; accepted 01/05/11. Author for correspondence: Shao-Chi Wu (e-mail: agarase@msn.com).

*Department of Tourism, Aletheia University, Taipei, Taiwan, R.O.C.

**Department of Food Science, National Taiwan Ocean University, Keelung, Taiwan, R.O.C

***Department of Food Science and Technology, Tung-Fang Design University, Kaohsiung, Taiwan, R.O.C.
It has been observed that the production of ROS in algae is stimulated by various environmental stresses, such as high light levels, heavy metals, high salt concentrations, UV irradiation, and other factors. Algae generally have higher antioxidative activity due to their higher content of various nonenzymatic antioxidant components, such as reduced glutathione (GSH), ascorbic acid, $\alpha$-tocopherol, $\beta$-carotenoids, flavonoids, hydroquinones, phycocyanin, proline, mannitol, myoinositol, phenolics, and/or polyamines [8]. As a result, algae have become good candidates as a source of natural antioxidants [17].

In recent years, our laboratory has focused on the preparation of four seaweed polysaccharide extracts (SwPSExts) from Gelidium sp., Gracilaria sp., Monostroma (Mon.) nitidum, and Porphyra dentate, or their seaweed-oligosaccharide-lysates (SwOSLys) source, as digested by the two agarases produced from A. salmonicida MAEF108 or Pseudomonas $(P$.) valicularis MA103, as well as their antioxidative properties, which were evaluated through several antioxidative tests $[15,16]$. Our laboratory purification of Agarase AS-II, as produced from A. salmonicida MAEF108, SwPSExts from Gracilaria sp., or Mon. nitidum has recently been further digested by Agarase AS-II. Thus, the current study focuses on the composition of SwOSLys, as derived from Gracilaria sp., or Mon. nitidum, and evaluates their antioxidative capacity by ferrouschelating antioxidant power.

\section{MATERIALS AND METHODS}

\section{Agarase-Producing Strain}

An agarase-producing strain, A. salmonicida MAEF108, with agar softening, was isolated from the seawater off the coast of Keelung, Taiwan [15].

\section{Preparation of Agarase AS-II from A. salmonicida MAEF108}

\section{1) Crude Agarases Preparation}

A modified method was derived from preliminary experiments of $\mathrm{Wu}$ et al. [16]. A. salmonicida MAEF108 produced the highest agarase activities in the following mediums 
and incubation conditions. A $2 \%$ activated culture of $A$. salmonicida MAEF108 was inoculated into $100 \mathrm{~mL}$ MMBMAEF108 of a medium composed of $0.40 \mathrm{~g}$ agar (Difco, MI, USA), $3.74 \mathrm{~g}$ marine broth 2216 (Difco), $0.60 \mathrm{~g}$ fructose (Sigma Chemical Co., MO, USA), $1.20 \mathrm{~g} \mathrm{NaCl}$ (Panreac, Barcelona, Spain), $50 \mathrm{mg}\left(\mathrm{NH}_{4}\right)_{2} \mathrm{HPO}_{4}$ (Panreac), and $12 \mathrm{mg}$ $\mathrm{MnCl}_{2}$ (Panreac) with its $\mathrm{pH}$ level adjusted to 6.0, which was suitable for a $250-\mathrm{mL}$ flask, at $20^{\circ} \mathrm{C}$ and a required $240 \mathrm{rpm}$ rotation. After a $12-\mathrm{h}$ incubation period, the culture suspension was centrifuged, at $4^{\circ} \mathrm{C}$ with $30,700 \times \mathrm{g}$, for $15 \mathrm{~min}$. The crude enzyme supernatant thus collected was named MAEF108agarases.

\section{2) Concentration via Ultrafiltration}

All procedures were carried out below $4^{\circ} \mathrm{C}$. Crude MAEF108-agarases were concentrated using a disposable modular tangential flow system, the Vivaflow50, with a 30$\mathrm{kDa}$ molecular weight cut-off (MWCO) membrane (Vivaflow 50, Vivascience, Hannover, Germany), which was confined with a peristaltic pump (Masterflex ${ }^{\circledR} 7553-10$, Masterflex, IL, USA) to promote the concentration of the crude MAEF108agarases solution, and with a flow rate maintained at 200 $\mathrm{mL} / \mathrm{min}$. When the ratio of the volume of concentrate, as compared with the original, reached 1:20, the agarases concentrate was dialyzed and subjected to the same concentration devices described above, against $10 \mathrm{X}$ volume, with $20 \mathrm{mM}$ Tris- $\mathrm{HCl}$ (Panreac) buffer (pH 6.2), which included $1.0 \mathrm{M} \mathrm{NaCl}$ and 2 $\mathrm{mM} \mathrm{CaCl}_{2}$ (Panreac). Finally, the agarases concentrate were filtrated using a $0.2-\mu \mathrm{m}$ membrane (Millex-GS, Millipore, MA, USA) for sterilization [16].

\section{3) Ion-Exchange}

The ion-exchange buffer (20 mM Tris- $\mathrm{HCl}, 2 \mathrm{mM} \mathrm{CaCl}$, $\mathrm{pH}$ 7.2) was first washed in a $400 \mathrm{~mm} \times 26 \mathrm{~mm}$ DE-52 ion exchange column, containing $100 \mathrm{~mL}$ ion-exchange DE-52 swollen gel (Whatman, Kent, UK), overnight at $4^{\circ} \mathrm{C}$. The concentrated crude MAEF108-agarases were then applied to the DE-52 column. Each of the 150 fractions collected $6 \mathrm{~mL}$ of eluent using the fraction collector (Retriever ${ }^{\mathrm{TM}} 500$, Isco Inc, NE, USA). The crude MAEF108-agarases were then eluted with a linear gradient of 0 to $1 \mathrm{M} \mathrm{NaCl}$, with $4 \mathrm{~mL}$ of eluent collected per fraction. After the gradient, $1 \mathrm{M}$ of $\mathrm{NaCl}$ was employed to elute and absorb all proteins [7]. Fractions with agarase activities were collected, and then concentrated using a disposable modular tangential flow system, Vivaflow 50 , with a $10 \mathrm{kDa}$ MWCO membrane (Vivaflow 50, Vivascience) and a peristaltic pump, as described above.

\section{Preparation of Seaweed-Oligosaccharide-Lysates (SwOSLys)}

\section{1) Seaweed Polysaccharide Extracts (SwPSExts)}

Deionized water was added to Gracilaria sp. or Mon. $n i$ tidum raw seaweed powder $(\mathrm{w} / \mathrm{w}=0.01)$, and then extracted at $121^{\circ} \mathrm{C}$ for 4 hours. After cooling to $37^{\circ} \mathrm{C}$, Cellulase R-10 (enzyme/substrate $=3 \%, \mathrm{w} / \mathrm{w}$ ) followed by Macerozyme R-10 (enzyme/substrate $=3 \%, \mathrm{w} / \mathrm{w}$ ), both purchased from Yalkult Honsha Co. Ltd. (Tokyo, Japan), were added for a 2-h digestion at $37^{\circ} \mathrm{C}$. Enzymes were inactivated for $10 \mathrm{~min}$ at $100^{\circ} \mathrm{C}$. Both Cellulase R-10 and Macerozyme R-10 served to decompose cellulose and hemicelluloses of seaweed tissue to single cells. Then, the Gracilaria sp. or Mon. nitidum polysaccharide supernatant was obtained by centrifugation $(2,000 \times \mathrm{g}$ for $30 \mathrm{~min}$ ), using a high-speed refrigerated centrifuge (Himac CR 21, Hitachi, Tokyo, Japan). The supernatant was then freezedried and named Gra or Mon, as detailed below, and stored at $-20^{\circ} \mathrm{C}$ for further use $[4,13]$.

\section{2) Preparation of Seaweed-Oligosaccharide-Lysates (SwOSLys)}

The 500-agarase-activity (AU) crude MAEF108-agarases were added to $1 \%$ Gra or Mon solutions, and digested at an optimal temperature $\left(40^{\circ} \mathrm{C}\right)$ for $120 \mathrm{~min}$, and referred to as Gra-C108 or Mon-C108. In addition, the 500-AU purified Agarase AS-II was added to $1 \%$ Gra or Mon solutions, and digested at an optimal temperature $\left(45^{\circ} \mathrm{C}\right)$ for $120 \mathrm{~min}$, and referred to as Gra-AS-II or Mon-AS-II. These lysates were freeze-dried and stored at $-20^{\circ} \mathrm{C}$ for further use [16].

\section{Quantification of Polyphenol}

Forty microliters of samples were added to $3.15 \mathrm{~mL}$ deionized water and $0.2 \mathrm{~mL}$ Folin-Ciocalteu's reagent for $6 \mathrm{~min}$. Then, $0.6 \mathrm{~mL}$ of $20 \% \mathrm{NaHCO}_{3}$ was added and reacted at room temperature for another $120 \mathrm{~min}$, and absorbance was then measured at $765 \mathrm{~nm}$. Polyphenol content was expressed as gallic acid equivalent (GAE) $\mu \mathrm{g} / \mathrm{mg}[1]$.

\section{Ferrous-Chelating Antioxidant Power}

The chelating effect on ferrous ions was determined according to a previous method [16]. The SwPSExts, or their agarase lysates, were mixed with methanol and $400 \mu \mathrm{M} \mathrm{FeCl}_{2}$ (Merck), followed by the addition of $2 \mathrm{mM}$ ferrozine (Sigma). After $10 \mathrm{~min}$, the absorbance of the mixture was determined as $562 \mathrm{~nm}$. Trolox was used as a positive control [9]. The chelating effect (\%) was calculated using the following equation:

$$
\begin{aligned}
\text { Chelating effect }(\%)= & {\left[1-\left(\mathrm{A}_{526} \text { of sample } \div \mathrm{A}_{526} \text { of blank }\right)\right.} \\
& \times 100]
\end{aligned}
$$

\section{Gel Permeation Chromatography (GPC)}

Concentrated Gra or Mon and their agarase lysates were applied to GPC columns (180 $\mathrm{mm} \times 15 \mathrm{~mm}$, Pharmacia) containing Sephacryl ${ }^{\circledR}$ S-200 gels (Pharmacia); or GPC columns $\left(1,000 \mathrm{~mm} \times 26 \mathrm{~mm}\right.$, Pharmacia) containing Sephadex ${ }^{\mathrm{TM}} \mathrm{G}-25$ gels (Pharmacia). Samples were eluted by degassed deionized water at ambient temperature, and fractions were then collected with the total sugar content measured by the phenolsulphuric-acid method using glucose as the standard at $\mathrm{A}_{480}$ [4]. 

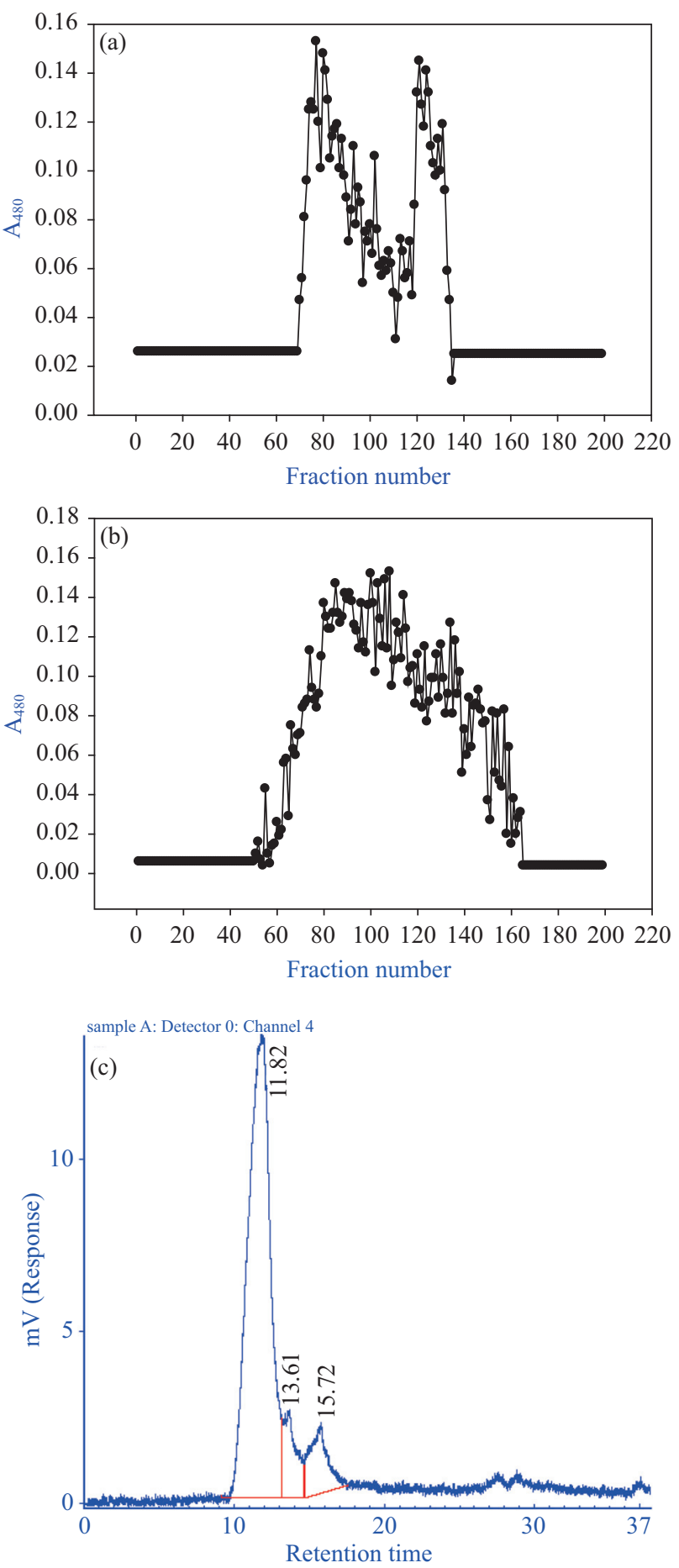

Fig. 1. (a) GPC profile with Sephacryl ${ }^{\circledR}$ S-200 gels, (b) GPC profile with Sephadex ${ }^{\mathrm{TM}}$ G-25 gels, (c) HPLC profile of Gracilaria sp. extract polysaccharides (Gra).

[GPC column size with Sephacryl ${ }^{\circledR}$ S-200 gels: $90 \mathrm{~cm} \times 2.6 \mathrm{~cm}$; fraction size: $3 \mathrm{~mL}$; flow rate: $0.5 \mathrm{~mL} / \mathrm{min}$; injected total sugar content: $3.65 \mathrm{mg} / \mathrm{mL}$; injection volume: $2 \mathrm{~mL}$ ].

[GPC column size with Sephadex ${ }^{\mathrm{TM}}$ G-25 gels: $90 \mathrm{~cm} \times 2.6 \mathrm{~cm}$; fraction size: $3 \mathrm{~mL}$; flow rate: $0.5 \mathrm{~mL} / \mathrm{min}$; injected total sugar content: $3.65 \mathrm{mg} / \mathrm{mL}$; injection volume: $2 \mathrm{~mL}$.

[HPLC column: Asahipak GS-320 HQ, size-exclusion column, $7.5 \mathrm{~mm} \times$ $300 \mathrm{~mm}$; column temperature: $30^{\circ} \mathrm{C}$; injection volume: $20 \mu \mathrm{L}$; flow rate: $0.4 \mathrm{~mL} / \mathrm{min}$; detector: $\mathrm{ELSD}$ ].

\section{High-Performance Liquid Chromatography (HPLC)}

The SEC-ELSD system consisted of a pump PU-1580 from Jasco (Tokyo, Japan), an Asahipak GS-320 HQ multi-mode column $(300 \times 7.6 \mathrm{~mm})$ preceded by an Asahipak GS-2G 7B guard column $(50 \times 7.6 \mathrm{~mm})$ (Shodex, Showa Denko, Tokyo, Japan), and an ELSD ZAM 3000 (Schambeck SFD GmbH, Bad Honnef, Germany). The temperature settings for the column oven and detector nebulizer were $30^{\circ} \mathrm{C}$ and $80^{\circ} \mathrm{C}$, respectively. Samples were injected via a CO-150 sampler with a $20-\mu \mathrm{L}$ sample loop (Rheodyne, Cotati, CA, USA). The mobile phase for the SEC was deionized water with a flowrate of $0.4 \mathrm{~mL} / \mathrm{min}$. For the $\mathrm{NH}_{2}$-HPLC-ELSD system, the same pump, ELSD injector sampler and sample loop were used as above. However, an Asahipak $\mathrm{NH}_{2} \mathrm{P}-504 \mathrm{E}$ multimode column $(250 \times 4.6 \mathrm{~mm})$ and an Asahipak $\mathrm{NH}_{2} \mathrm{P}-50 \mathrm{G} 4 \mathrm{~A}$ $(10 \times 4.6 \mathrm{~mm})($ Shodex, Showa Denko, Tokyo, Japan) were used, where the temperature settings for the column oven and detector nebulizer were $40^{\circ} \mathrm{C}$ and $80^{\circ} \mathrm{C}$, respectively. The mobile phase was methanol: $\mathrm{H}_{2} \mathrm{O}=30: 70$ with a flow-rate of $0.5 \mathrm{~mL} / \mathrm{min}$. Chrom Manager 5.8 software from Analytical Based Development Center (Taichung, Taiwan) was used for online data monitoring and analysis [6].

\section{Statistical Analysis}

All antioxidative results of the samples are expressed as mean $\pm \mathrm{SD}(\mathrm{n}=3)$. Data were analyzed by one-way analysis of variance (ANOVA). When ANOVA identified differences among the groups, multiple comparisons among the means were performed, using Duncan's new multiple range tests. Statistical significance was determined by setting the aggregate type I error at $5 \%(p<0.05)$ for each set of comparisons, using the Statistical Analysis System software package [10].

\section{RESULTS AND DISCUSSION}

\section{Composition of Seaweed Polysaccharide Extracts or Their Lysates}

To monitor the components of Gra samples, Gra-C108, Gra-AS-II, Mon, Mon-C108, and Mon-AS-II were applied to gel permeation chromatography, using Sephacryl ${ }^{\circledR}$ S-200 gels, as shown in Fig. 1(a) to Fig. 6(a); and using Sephadex ${ }^{\mathrm{TM}}$ G-25 gels, as shown in Fig. 1(b) to Fig. 6(b). HPLC was performed using an Asahipak GS-320 HQ size-exclusion column to monitor the components of SwPSExts, and their agarase lysate samples, as shown in Fig. 1(c) to Fig. 6(c). As can be seen, the GPC profile with Sephacryl ${ }^{\mathbb{B}}$ S-200 gels of Gra [Fig. 1(a)], Gra-C108 [Fig. 2(a)], and Gra-AS-II [Fig. 3(a)] shows major peaks of neoagarooligosaccharides for fractions 120-140, 140180 , and 120-160, respectively. Moreover, the neoagarooligosaccharide fractions of Gra, Gra-C108, and Gra-AS-II bring in absorption values of $0.15,0.70$, and 0.20 at $\mathrm{A}_{480}$ of 130,160 , and 140, respectively; implying neoagarooligosaccharide contents in the order of Gra-C108 $>$ Gra-AS-II $>$ Gra. The GPC profile with Sephacryl ${ }^{\mathbb{B}}$ S-200 gels of Mon [Fig. 4(a)] and 

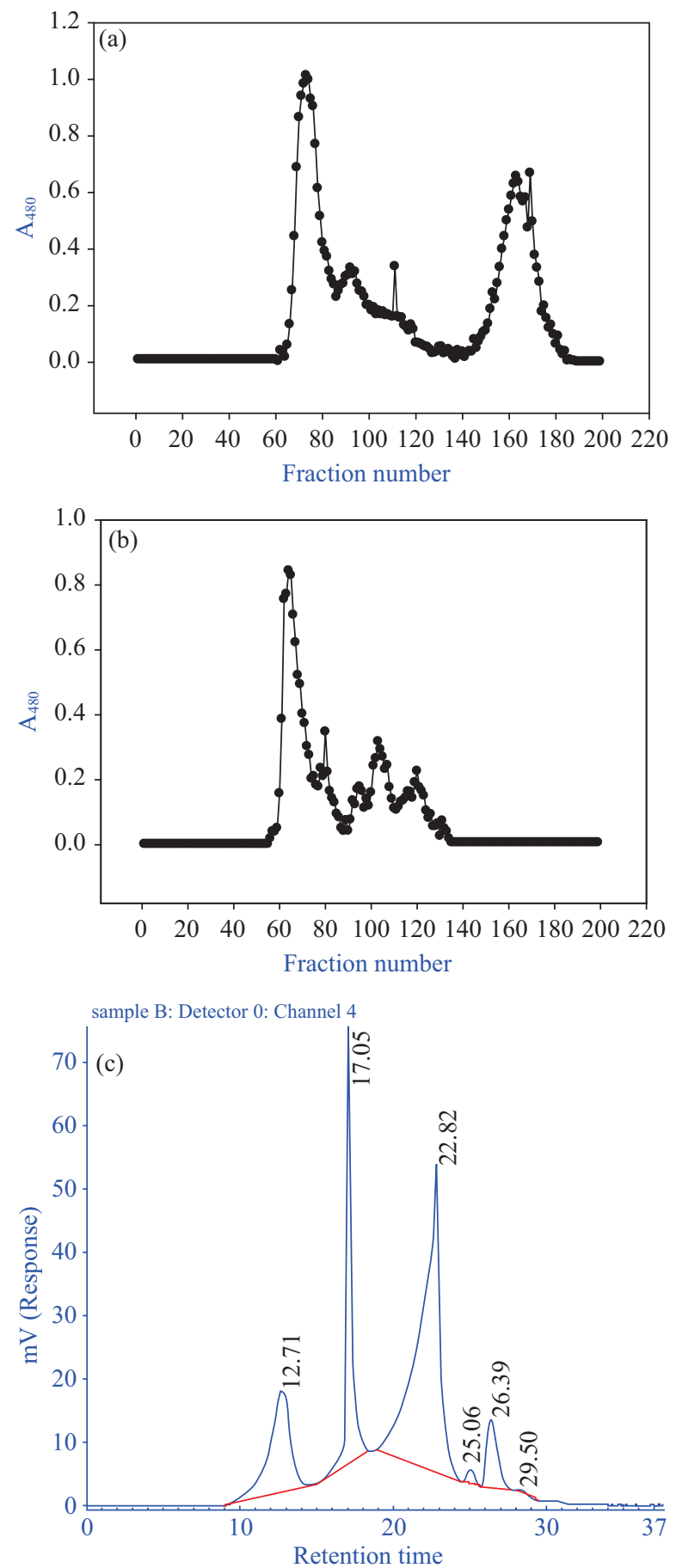

Fig. 2. (a) GPC profile with Sephacryl ${ }^{\circledR}$ S-200 gels, (b) GPC profile with Sephadex $^{\mathrm{TM}}$ G-25 gels, (c) HPLC profile of Gracilaria $\mathrm{sp}$. extracted polysaccharides digested by $A$. salmonicida MAEF108 crude agarases (Gra-C108).

[GPC column size with Sephacryl ${ }^{\circledR}$ S-200 gels: $90 \mathrm{~cm} \times 2.6 \mathrm{~cm}$; fraction size: $3 \mathrm{~mL}$; flow rate: $0.5 \mathrm{~mL} / \mathrm{min}$; injected total sugar content: $3.65 \mathrm{mg} / \mathrm{mL}$; injection volume: $2 \mathrm{~mL}$.

[GPC column size with Sephadex ${ }^{\mathrm{TM}} \mathrm{G}-25$ gels: $90 \mathrm{~cm} \times 2.6 \mathrm{~cm}$; fraction size: $3 \mathrm{~mL}$; flow rate: $0.5 \mathrm{~mL} / \mathrm{min}$; injected total sugar content: $3.65 \mathrm{mg} / \mathrm{mL}$; injection volume: $2 \mathrm{~mL}$.

[HPLC column: Asahipak GS-320 HQ, size-exclusion column, $7.5 \mathrm{~mm} x$ $300 \mathrm{~mm}$; column temperature: $30^{\circ} \mathrm{C}$; injection volume: $20 \mu \mathrm{L}$; flow rate: $0.4 \mathrm{~mL} / \mathrm{min}$; detector: ELSD].
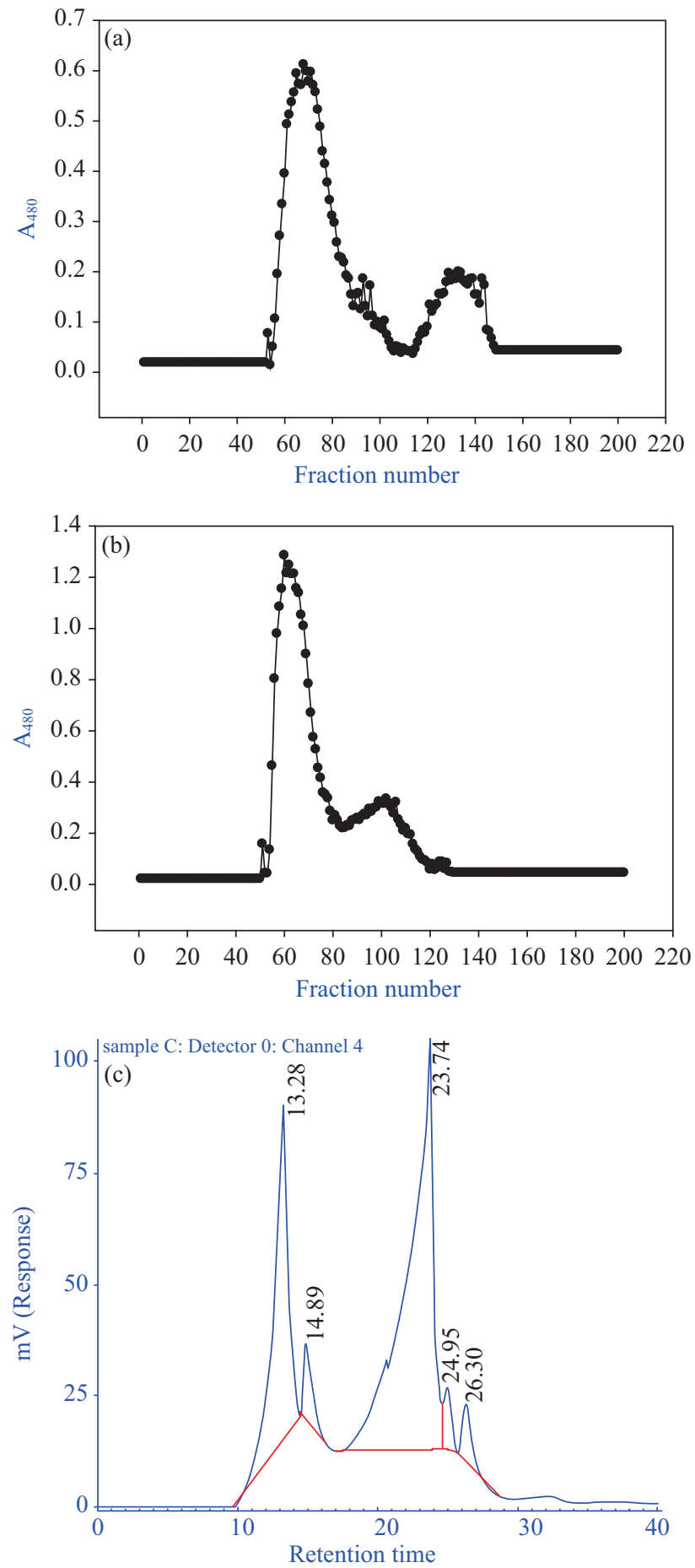

Fig. 3. (a) GPC profile with Sephacryl ${ }^{\circledR}$ S-200 gels, (b) GPC profile with Sephadex $^{\text {TM }}$ G-25 gels, (c) HPLC profile of Gracilaria sp. extracted polysaccharides digested by Agarase AS-II (Gra-AS-II).

[GPC column size with Sephacry ${ }^{\circledR} S-200$ gels: $90 \mathrm{~cm} \times 2.6 \mathrm{~cm}$; fraction size: $3 \mathrm{~mL}$; flow rate: $0.5 \mathrm{~mL} / \mathrm{min}$; injected total sugar content: $3.65 \mathrm{mg} / \mathrm{mL}$; injection volume: $2 \mathrm{~mL}$ ].

[GPC column size with Sephadex ${ }^{\mathrm{TM}}$ G-25 gels: $90 \mathrm{~cm} \times 2.6 \mathrm{~cm}$; fraction size: $3 \mathrm{~mL}$; flow rate: $0.5 \mathrm{~mL} / \mathrm{min}$; injected total sugar content: $3.65 \mathrm{mg} / \mathrm{mL}$; injection volume: $2 \mathrm{~mL}$ ].

[HPLC column: Asahipak GS-320 HQ, size-exclusion column, $7.5 \mathrm{~mm} \times$ $300 \mathrm{~mm}$; column temperature: $30^{\circ} \mathrm{C}$; injection volume: $20 \mu \mathrm{L}$; flow rate: $0.4 \mathrm{~mL} / \mathrm{min}$; detector: $\mathrm{ELSD}$. 

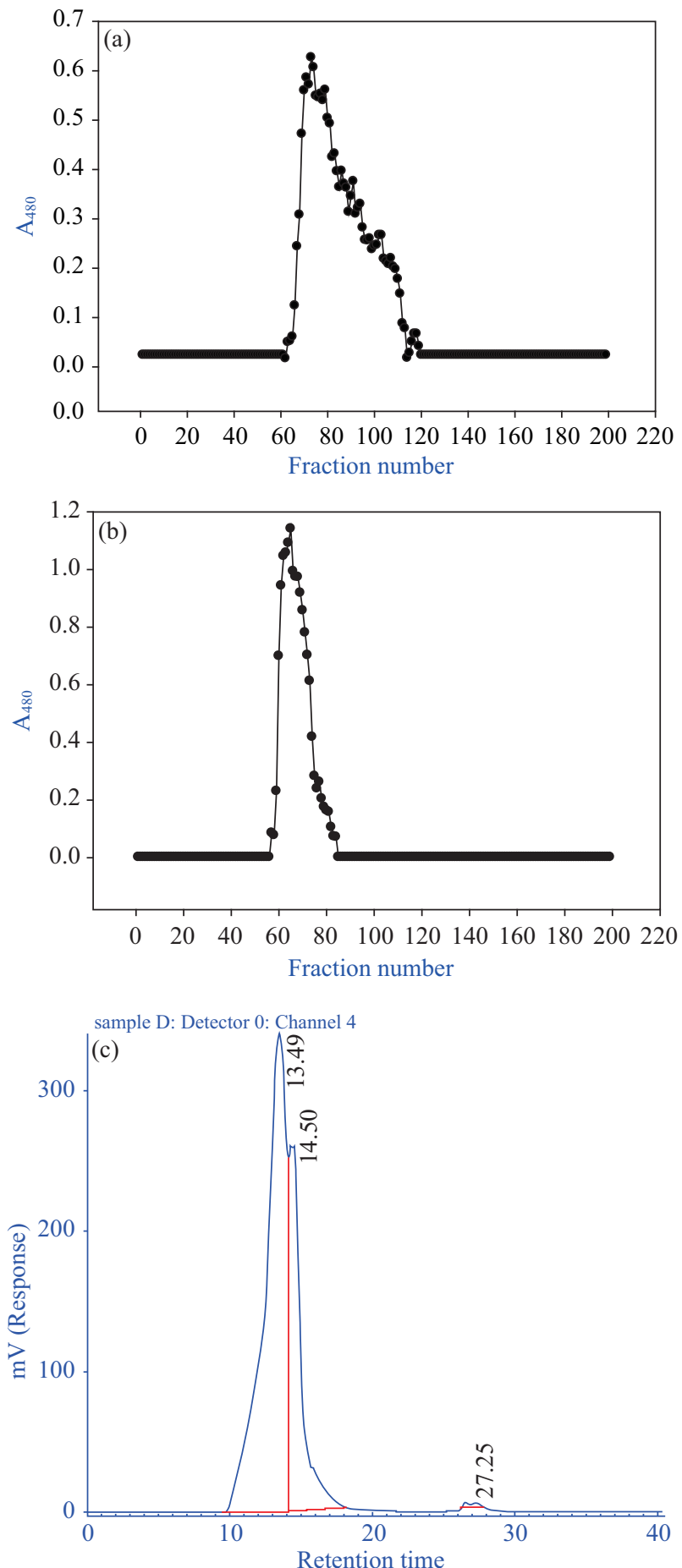

Fig. 4. (a) GPC profile with Sephacryl ${ }^{\circledR}$ S-200 gels, (b) GPC profile with Sephadex $^{\text {TM }}$ G-25 gels, (c) HPLC profile of Mon. nitidum extracted polysaccharides (Mon).

[GPC column size with Sephacryl ${ }^{\circledast}$ S-200 gels: $90 \mathrm{~cm} \times 2.6 \mathrm{~cm}$; fraction size: $3 \mathrm{~mL}$; flow rate: $0.5 \mathrm{~mL} / \mathrm{min}$; injected total sugar content: $3.65 \mathrm{mg} / \mathrm{mL}$; injection volume: $2 \mathrm{~mL}$.

[GPC column size with Sephadex ${ }^{\mathrm{TM}} \mathrm{G}-25$ gels: $90 \mathrm{~cm} \times 2.6 \mathrm{~cm}$; fraction size: $3 \mathrm{~mL}$; flow rate: $0.5 \mathrm{~mL} / \mathrm{min}$; injected total sugar content: $3.65 \mathrm{mg} / \mathrm{mL}$; injection volume: $2 \mathrm{~mL}$.

[HPLC column: Asahipak GS-320 HQ, size-exclusion column, $7.5 \mathrm{~mm} \times$ $300 \mathrm{~mm}$; column temperature: $30^{\circ} \mathrm{C}$; injection volume: $20 \mu \mathrm{L}$; flow rate: $0.4 \mathrm{~mL} / \mathrm{min}$; detector: $\mathrm{ELSD}$.
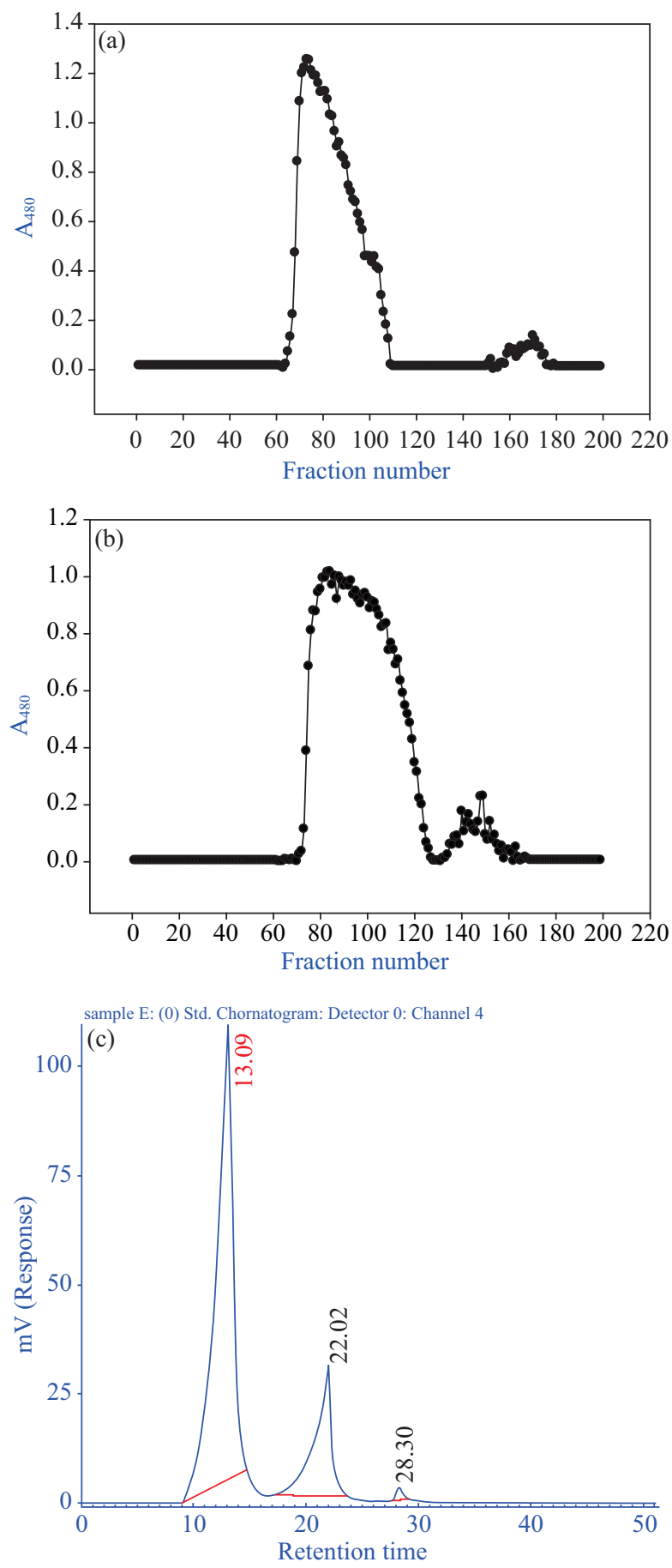

Fig. 5. (a) GPC profile with Sephacryl ${ }^{\circledR}$ S-200 gels, (b) GPC profile with Sephadex ${ }^{\mathrm{TM}}$ G-25 gels, (c) HPLC profile of Mon. nitidum extracted polysaccharides digested by $A$. salmonicida MAEF108 crude agarases (Mon-C108).

[GPC column size with Sephacryl ${ }^{\circledR}$ S-200 gels: $90 \mathrm{~cm} \times 2.6 \mathrm{~cm}$; fraction size: $3 \mathrm{~mL}$; flow rate: $0.5 \mathrm{~mL} / \mathrm{min}$; injected total sugar content: $3.65 \mathrm{mg} / \mathrm{mL}$; injection volume: $2 \mathrm{~mL}$ ].

[GPC column size with Sephadex ${ }^{\mathrm{TM}}$ G-25 gels: $90 \mathrm{~cm} \times 2.6 \mathrm{~cm}$; fraction size: $3 \mathrm{~mL}$; flow rate: $0.5 \mathrm{~mL} / \mathrm{min}$; injected total sugar content: $3.65 \mathrm{mg} / \mathrm{mL}$; injection volume: $2 \mathrm{~mL}$ ].

[HPLC column: Asahipak GS-320 HQ, size-exclusion column, $7.5 \mathrm{~mm} \times$ $300 \mathrm{~mm}$; column temperature: $30^{\circ} \mathrm{C}$; injection volume: $20 \mu \mathrm{L}$; flow rate: $0.4 \mathrm{~mL} / \mathrm{min}$; detector: $\mathrm{ELSD}$. 

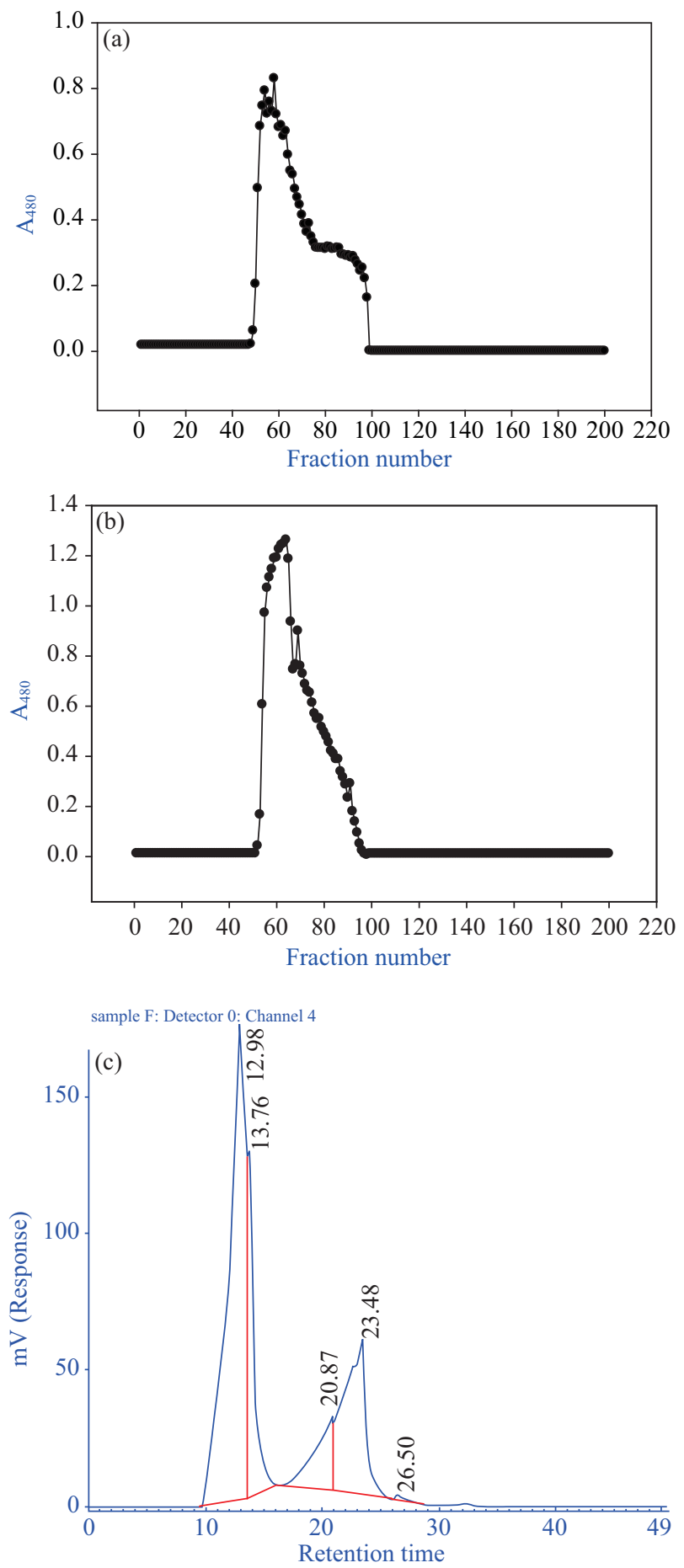

Fig. 6. (a) GPC profile with Sephacryl ${ }^{\circledR}$ S-200 gels, (b) GPC profile with Sephadex $^{\text {TM }}$ G-25 gels, (c) HPLC profile of Mon. nitidum extracted polysaccharides digested by Agarase AS-II (Mon-AS-II).

[GPC column size with Sephacry ${ }^{\circledR} S-200$ gels: $90 \mathrm{~cm} \times 2.6 \mathrm{~cm}$; fraction size: $3 \mathrm{~mL}$; flow rate: $0.5 \mathrm{~mL} / \mathrm{min}$; injected total sugar content: $3.65 \mathrm{mg} / \mathrm{mL}$; injection volume: $2 \mathrm{~mL}$ ].

[GPC column size with Sephadex ${ }^{\mathrm{TM}} \mathrm{G}-25$ gels: $90 \mathrm{~cm} \times 2.6 \mathrm{~cm}$; fraction size: $3 \mathrm{~mL}$; flow rate: $0.5 \mathrm{~mL} / \mathrm{min}$; injected total sugar content: $3.65 \mathrm{mg} / \mathrm{mL}$; injection volume: $2 \mathrm{~mL}$.

[HPLC column: Asahipak GS-320 HQ, size-exclusion column, $7.5 \mathrm{~mm} \times$ $300 \mathrm{~mm}$; column temperature: $30^{\circ} \mathrm{C}$; injection volume: $20 \mu \mathrm{L}$; flow rate: $0.4 \mathrm{~mL} / \mathrm{min}$; detector: $\mathrm{ELSD}$ ].
Mon-C108 [Fig. 5(a)] shows major peaks of neoagarooligosaccharide for fractions 110-120 and 150-180, respectively; while the GPC profile with Sephacryl ${ }^{\circledR}$ S-200 gels of MonAS-II.

Fig. 6(a) shows no apparent peak of neoagarooligosaccharides. Moreover, the neoagarooligosaccharide fractions of Mon and Mon-C108 bring in absorption values of 0.05 and 0.15 at $\mathrm{A}_{480}$ of 115 and 165 , respectively; implying neoagarooligosaccharide contents in the order of Mon-C108 > Mon > Mon-AS-II. The GPC profile with Sephadex ${ }^{\mathrm{TM}} \mathrm{G}-25$ gels of Gra [Fig. 1(b)] shows disorderly distribution of neoagarooligosaccharides all throughout. Gra-C108 [Fig. 2(b)] shows major peaks for fractions 60-80, 90-110, 110-130, and 130-140, while Gra-AS-II [Fig. 3(b)] shows major peaks for fractions 60-80, 80-120, and120-130. The GPC profile with Sephadex ${ }^{\mathrm{TM}}$ G-25 gels presents more distinct peak in Gra-AS-II than in Gra-C108 and Gra. The GPC profile with Sephadex ${ }^{\mathrm{TM}}$ G-25 gels of Mon [Fig. 4(b)] shows major peak for fraction 50-90. Mon-C108 [Fig. 5(b)] shows major peak for fractions 70-125 and 125-160, while Mon-AS-II [Fig. 6(b)] shows major peak for fraction 50-95.

GPC could only monitor the trends of SwPSExt digestion, whether they used crude MAEF108-agarases or Agarase AS-II. Both Sephacryl ${ }^{\mathbb{R}}$ S-200 gels and Sephadex ${ }^{\mathrm{TM}}$ G-25 gels were able to monitor different molecular weights, focused on 1,00080,000 or $100-5,000$, respectively. Before gel permeation chromatography by Sephadex ${ }^{\mathrm{TM}}$ G-25, it should be known all polysaccharides and oligosaccharides of SwPSExts or SwOSLys. After Sephacryl ${ }^{\circledR}$ S-200 gels employed for gel permeation chromatography, it could be more easy focus on fractions that contain oligosaccharides of SwOSLys to next gel permeation chromatography used Sephadex ${ }^{\mathrm{TM}}$ G-25. These two GPC gels were able to determine the carbohydrate molecular weight distribution of SwPSExts and their agarase lysates, and revealed that HPLC had higher sensitivity and could monitor the traces of oligosaccharides in agarase lysates better than GPC could. HPLC revealed that there were neoagarohexaose [Retention time $(\mathrm{RT})=25.06 \mathrm{~min}]$ and neoagarotetraose $(\mathrm{RT}=$ $26.32 \mathrm{~min}$ ) in both Gra-C108 and Gra-AS-II [Fig. 2(c), and Fig. 3(c)]. The HPLC profile of Gra-C108 [Fig. 2 (c)] was more complex than that of Gra-AS-II [Fig. 3(c)]. Such results may be caused by $A$. salmonicida MAEF108 crude agarases, which contain multiple enzymes and have thus additional digestive functions. When monitored by GPC, Mon-C108 showed one major peak and one minor peak in both Sephacryl ${ }^{\circledR} \mathrm{S}-200$ and Sephadex ${ }^{\mathrm{TM}}$ G-25 gels [Fig. 5(a) and (b), respectively], while Mon-AS-II showed one major peak, in both Sephacryl ${ }^{\circledR}$ S-200 and Sephadex ${ }^{\mathrm{TM}}$ G-25 gels [Fig. 6(a) and(b), respectively]. Mon. nitidum showed no significant changes in the reduction of sugar content when its polysaccharide was digested by Agarase AS-II. It exhibit crude MAEF108-agarases that could rather digested Mon polysaccharides than utilized purified Agarase AS-II. When analyzed by HPLC, Mon also showed traces digested by Agarase AS-II, which produced rare non-reducing oligosaccharide fragments $(\mathrm{RT}=23.48 \mathrm{~min})$. 
Table 1. Polyphenolic compound contents and $\mathrm{Fe}^{2+}$ ion chelating effects of two algal extracted polysaccharides or their agarase lysates ${ }^{1}$.

\begin{tabular}{|c|c|c|c|}
\hline Sample & $\begin{array}{c}\text { GAE/total } \\
\text { sugar } \\
(\mu \mathrm{g} / \mathrm{mg})^{3}\end{array}$ & $\begin{array}{c}\mathrm{Fe}^{2+} \text { Chelating } \\
\text { effect } \\
(\%)\end{array}$ & $\begin{array}{c}\text { EDTA } \\
\text { equivalent } \\
(\mathrm{ppm})\end{array}$ \\
\hline Gra & $363.4 \pm 2.0^{\mathrm{a}^{*}}$ & $62.5 \pm 2.5^{\mathrm{c}}$ & $5.3 \pm 0.2^{\mathrm{c}}$ \\
\hline Gra-C108 & $586.1 \pm 1.01^{\mathrm{c}}$ & $93.1 \pm 1.2^{\mathrm{e}}$ & $7.5 \pm 0.1^{\mathrm{e}}$ \\
\hline Gra-AS-II & $580.4 \pm 5.1^{\mathrm{c}}$ & $78.5 \pm 0.7^{\mathrm{d}}$ & $6.4 \pm 0.1^{\mathrm{d}}$ \\
\hline Mon & $358.1 \pm 1.8^{\mathrm{a}}$ & $21.3 \pm 1.8^{\mathrm{a}}$ & $2.4 \pm 0.4^{\mathrm{a}}$ \\
\hline Mon-C108 & $570.8 \pm 1.0^{\mathrm{bc}}$ & $32.0 \pm 0.1^{\mathrm{b}}$ & $3.1 \pm 0.0^{\mathrm{b}}$ \\
\hline Mon-AS-II & $561.8 \pm 3.0^{\mathrm{bc}}$ & $27.3 \pm 0.9^{\mathrm{b}}$ & $2.8 \pm 0.1^{\mathrm{b}}$ \\
\hline
\end{tabular}

${ }^{1}$ : Each value is the means \pm standard deviation $(n=3)$. Data bearing different superscript letters in the same column are significantly different $(p<0.05)$.

2: Gra: Gracilaria sp. extracted polysaccharides; Gra-C108: Gracilaria sp. extracted polysaccharide lysates that digested by $A$. salmonicida MAEF108 crude agarases; Gra-AS-II: Gracilaria sp. extracted polysaccharide lysates that digested by Agarase AS-II; Mon: Mon. nitidum extracted polysaccharides; Mon-C108: Mon. nitidum extracted polysaccharide lysates that digested by A. salmonicida MAEF108 crude agarases; Mon-AS-II: Mon. nitidum extracted polysaccharide lysates that digested by Agarase AS-II.

${ }^{3}$ : Polyphenolic compound contents expressed as gallic acid equivalent.

In addition, neoagarooligosaccharide was absent [Fig. 6(c)].

\section{Polyphenol contents and Ferrous-Chelating Antioxidant Power of SwPSExts, and Their Agarase Lysates}

Wu et al. [16] fractionated algal oligosaccharide lysates and found that the polyphenolic fractions showed more antioxidative abilities, thus the polyphenolic compounds in Gra, GraC108, Gra-AS-II, Mon, Mon-C108, and Mon-AS-II were evaluated. The results shown in Table 1 are polyphenolic compound contents expressed as gallic acid equivalent (GAE). The GAE of the SwPSExt Gra was $363.4 \mu \mathrm{g} / \mathrm{mg}$, and their agarase lysates, Gra-C108 or Gra-AS-II, were increased to 586.1 or $580.4 \mu \mathrm{g}$ GAE per mg of total sugar, respectively, without significant difference $(p<0.05)$. GAE of SwPSExt Mon was $358.1 \mu \mathrm{g} / \mathrm{mg}$, while that of their agarase lysates, Mon-C108 and Mon AS-II, were 570.8 and $561.8 \mathrm{mg}$ per mg total sugar, respectively, without significant difference $(p<$ $0.05)$.

The antioxidant potential of sulfated polysaccharides of brown seaweed Fucus vesiculosus examined using ferric reducing antioxidant power (FRAP) assay was found to be higher than that of the agar-like sulfated galactans from red seaweed [9]. Jimenez-Escrig et al. [5] also indicated that algal extracts that have chelating $\mathrm{Fe}^{2+}$ effects may due to polyphenolic compound contents and dose dependent. Chelating effects of SwPSExts and their agarase lysates on $\mathrm{Fe}^{2+}$ were further evaluated. Percentages of $\mathrm{Fe}^{2+}$-chelating effects, and its EDTA equivalent, are shown in Table 1. The $\mathrm{Fe}^{2+}$-chelating effect on Gra was $62.5 \%$ (equivalent to 5.3 ppm EDTA); and after digestion by $A$. salmonicida MAEF108 crude agarases, the chelating effect rose to $93.1 \%$ (equivalent to $7.5 \mathrm{ppm}$ EDTA). The chelating effect on Gra-AS-II was not as strong as that on Gra-C108, though it still reached $78.5 \%$ (equivalent to 6.4 ppm EDTA). Mon showed chelating effect of $21.3 \%$; and after digestion by enzyme, Mon-C108 and Mon-AS-II showed $\mathrm{Fe}^{2+}$-chelating effect of $32.0 \%$ and $27.3 \%$, respectively. Heo et al. [3] reported that the total soluble polyphenol content of brown seaweeds, hydrolyzed by carbohydrases or protease, performed better antioxidative abilities than the unhydrolyzed ones. Algal oligosaccharide lysate, as derived from Porphyra dentate, was fractionated by $\mathrm{Wu}$ et al. [16], who reported that the polyphenolic fraction possessed antioxidative properties, when monitored via their $\mathrm{Fe}^{2+}$-chelating capacities. Comparison of the $\mathrm{Fe}^{2+}$-chelating effects on GraC108, Gra-AS-II, Mon-C108, and Mon-AS-II showed that not only polyphenolic compounds but also sulfated polysaccharides possessed antioxidative properties. Wang et al. [11] also separated agar oligosaccharides AOS-1, AOS-2, and AOS-3 by ethanol fractionation and anion exchange chromatography. The agar oligosaccharides exhibited antioxidative activities in several antioxidative tests, such as scavenging hydroxyl free radicals and superoxide anion radicals, and inhibiting lipid peroxidation. The fragment of the sulfate group showed stronger antioxidative activities than that without the sulfate group. Wang et al. [11] indicated that antioxidative activities were closely related to the molecular mass of the agar oligosaccharides and the substitute groups bound in the carbohydrate ring. Therefore, neoagarooligosaccharides in both Gra-C108 and Gra-AS-II could possess larger antioxidative capacities than Mon-C108 and Mon-AS-II, without neoagarooligosaccharides. Moreover, neoagarobiose, neoagarotetraose and neoagaorohexaose show $\mathrm{Fe}^{2+}$-chelating effects of $47.0 \pm 1.1,25.1 \pm 2.1$, and $2.5 \pm 1.5 \%$, revealing that neoagarooligosaccharides of low molecular weight have greater chelating effect on ferrous ion than those of high molecular weight [14]. Comparing their HPLC profiles also shows higher neoagarobiose content in their SwPSExts or agarase lysates with greater chelating effect on ferrous ion.

\section{CONCLUSION}

The authors are grateful to the National Science Council, Taiwan for support of this work (Grant No. NSC 95-2313B019-025-MY3).

\section{REFERENCES}

1. Athukorala, Y., Lee, K. W., and Song, C., "Potential antioxidant activity of marine red alga Grateloupia filicina extracts," Journal of Food Lipids, Vol. 10, pp. 251-265 (2003).

2. Cirelli, C., "Sleep disruption, oxidative stress, and aging: New insights from fruit flies," Proceedings of the National Academy of Sciences of the United States of America, Vol. 103, pp. 13901-13902 (2007). 
3. Heo, S. J., Lee, K. W., Song, C. B., and Jeon, Y. J. “Antioxidant activity of enzymatic extracts from brown seaweeds," Algae, Vol. 18, pp. 71-81 (2003).

4. Hung, Y. H., Studies on Antioxidation of Lactic Acid Fermented GrateLoupia Filicina, Master Thesis, Department of Food Science, National Taiwan Ocean University. Keelung, Taiwan, ROC (2005). (in Chinese)

5. Jimenez-Escrig, A., Jimenez-Jimenez, I., Pulido, R., and Saura-Calixto, F., "Antioxidant activity of fresh and processed edible seaweeds," Journal of the Science of Food and Agriculture, Vol. 81, pp. 530-534 (2001).

6. Kazłwski, B., Pan, C.-L., and Ko, Y.-T., "Separation and quantification of neoagaro- and agaro-oligosaccharide products generated from agarose digestion by $\beta$-agarase and $\mathrm{HCl}$ in liquid chromatography systems," Carbohydrate Research, Vol. 343, pp. 2443-2450 (2008).

7. Liu, Y. H., Liang, H. J., Cheng, H. C., Liu, Y. W., and Hou, W. C., “Comparisons of in vitro antioxidant activities of storage proteins in tuber of two Dioscorea species," Botanical Studies, Vol. 47, pp. 231-237 (2006).

8. Robards, K., Prenzler, P. D., Tucker, G., Swatsitang, P., and Glover, W., "Phenolic compounds and their role in oxidative processes in fruits," Food Chemistry, Vol. 66, pp. 401-436 (1999).

9. Ruperez, P., Ahrazem, O., and Leal, J. A., "Potential antioxidant capacity of sulfated oligosaccharides from the edible marine brown seaweed Fucus vesiculosus," Journal of Agricultural and Food Chemistry, Vol. 50, pp. 840-845 (2002)

10. SAS Institute, User's Guide, Release 8.0 ed., SAS Institute, Cary, N.C. (1997).
11. Wang, J. G., Jiang, X. L., Mou, H. J., and Guan, H. S., “Anti-oxidation of agar oligosaccharides produced by agarase from a marine bacterium," Journal of Applied Phycology, Vol. 16, pp. 333-340 (2004).

12. Wu, J.-T. and Wu, L.-L., "Chronic systemic inflammation leading eventually to myocardial infarction, stroke, COPD, renal failure and cancer is induced by multiple risk factors," Journal of Biomedical and Laboratory Sciences, Vol. 19, pp. 1-5 (2007).

13. Wu, S.-C., The Studies on the Production Conditions of Agarases Produced from Marine Bacteria and Profiles of Oligosaccharides Derived from the Digestion of the Algal Polysaccharides by Agarase, Master Thesis, Department of Food Science, National Taiwan Ocean University, Keelung, Taiwan, ROC (1999). (in Chinese)

14. Wu, S.-C., Studies on Biological Activity of Algal Lysates Derived from Agarases Digested and Their Fermentation Products, Ph.D. Dissertation, Department of Food Science, National Taiwan Ocean University, Keelung, Taiwan, ROC (2005). (in Chinese)

15. Wu, S.-C. and Pan, C.-L., "Preparation of algal-oligosaccharide mixtures by bacterial agarases and their antioxidative properties," Fisheries Science, Vol. 70, pp. 1164-1173 (2004).

16. Wu, S.-C., Wen, T.-N., and Pan, C.-L., "Alga-oligosaccharide-lysates prepared by two bacterial agarases stepwise hydrolyzed and their antioxidative properties," Fisheries Science, Vol. 71, pp. 1149-1159 (2005).

17. Zubia, M., Robledo, D., and Freile-Pelegrin, Y., "Antioxidant activities in tropical marine macroalgae from the Yucatan Peninsula, Mexico," Journal of Applied Phycology, Vol. 19, pp. 449-458 (2007) 